\title{
Assessment of Fleet Inventory for Naval Air Station Whidbey Island: Task 1
}

Stephen Schey Jim Francfort

January 2015

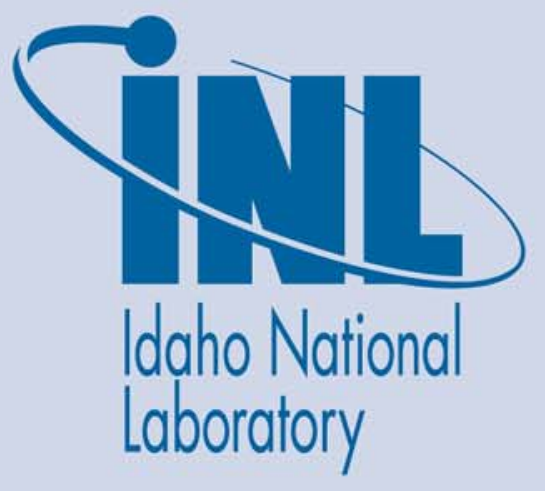

The INL is a U.S. Department of Energy National Laboratory operated by Battelle Energy Alliance 


\section{DISCLAIMER}

This information was prepared as an account of work sponsored by an agency of the U.S. Government. Neither the U.S. Government nor any agency thereof, nor any of their employees, makes any warranty, expressed or implied, or assumes any legal liability or responsibility for the accuracy, completeness, or usefulness, of any information, apparatus, product, or process disclosed, or represents that its use would not infringe privately owned rights. References herein to any specific commercial product, process, or service by trade name, trade mark, manufacturer, or otherwise, does not necessarily constitute or imply its endorsement, recommendation, or favoring by the U.S. Government or any agency thereof. The views and opinions of authors expressed herein do not necessarily state or reflect those of the U.S. Government or any agency thereof. 


\title{
Assessment of Fleet Inventory for Naval Air Station Whidbey Island: Task 1
}

\author{
Stephen Schey \\ Jim Francfort ${ }^{2}$ \\ ${ }^{1}$ Stephen Schey, Project Manager, Infrastructure Planning and Analysis, Intertek Testing Services, \\ North America, Phoenix, AZ \\ ${ }^{2}$ Jim Francfort, Vehicle Systems Principal Investigator, Idaho National Laboratory operated by \\ Battelle Energy Alliance, Idaho Falls, ID \\ January 2015
}

Idaho National Laboratory

Idaho Falls, Idaho 83415

http://avt.inl.gov

Prepared for the

U.S. Department of Energy

Office of Nuclear Energy

Under DOE Idaho Operations Office

Contract DE-AC07-05ID14517 


\section{ABSTRACT}

Battelle Energy Alliance, LLC, managing and operating contractor for the U.S. Department of Energy's Idaho National Laboratory, is the lead laboratory for U.S. Department of Energy's advanced vehicle testing. Battelle Energy Alliance, LLC contracted with Intertek Testing Services, North America (Intertek) to conduct several U.S. Department of Defense-based studies to identify potential U.S. Department of Defense transportation systems that are strong candidates for introduction or expansion of plug-in electric vehicles (PEVs).

Task 1includes a survey of the inventory of non-tactical fleet vehicles at Naval Air Station Whidbey Island (NASWI) to characterize the fleet. This information and characterization are used to select vehicles for monitoring that takes place during Task 2. This monitoring involves data logging of vehicle operation in order to identify the vehicle's mission and travel requirements. Individual observations of these selected vehicles provide the basis for recommendations related to PEV adoption. It also identifies whether a battery electric vehicle or plug-in hybrid electric vehicle (collectively referred to as PEVs) can fulfill the mission requirements and provide observations related to placement of PEV charging infrastructure.

This report provides the results of the assessments and observations of the current non-tactical fleet, fulfilling the Task 1 requirements.

Intertek acknowledges the support of Idaho National Laboratory, Naval Facilities Engineering Command Northwest, and NASWI fleet managers and personnel for participation in this study.

Intertek is pleased to provide this report and is encouraged by enthusiasm and support from Naval Facilities Engineering Command Northwest personnel. 


\section{EXECUTIVE SUMMARY}

Federal agencies are mandated ${ }^{a}$ to purchase alternative fuel vehicles, increase consumption of alternative fuels, and reduce petroleum consumption. Available plug-in electric vehicles (PEVs) provide an attractive option in the selection of alternative fuel vehicles. PEVs, which consist of both battery electric vehicles and plug-in hybrid electric vehicles, have significant advantages over internal combustion vehicles in terms of energy efficiency, reduced petroleum consumption, and reduced production of greenhouse gas emissions, and they provide performance benefits with quieter, smoother operation. This study intended to evaluate the extent to which Naval Air Station Whidbey Island (NASWI) could convert part or all of their fleet of vehicles from petroleum-fueled vehicles to PEVs.

The study begins with an assessment of the existing non-tactical fleet of vehicles at NASWI to characterize its current components in order to select representative vehicles for an in-depth assessment, leading to specific results for these selected vehicles and wider extrapolation to the full fleet of vehicles.

NASWI is located on Whidbey Island on the Puget Sound in Washington State. It is the premier naval aviation installation in the Pacific Northwest and home of all Navy tactical electronic attack squadrons flying the EA-6B Prowler and EA-18G Growler. In addition, there are four P-3 Orion Maritime Patrol squadrons and two Fleet Reconnaissance squadrons flying the EP-3E Aries. ${ }^{b}$

PEVs that are currently commercially available cannot replace certain vehicles and missions, such as those requiring heavy-duty trucks and specialty usage vehicles. However, the NASWI non-tactical fleet contains 175 vehicles for which counterpart PEVs are currently available or are expected to be available in the near future. From these 175 vehicles, 60 vehicles will be selected for further monitoring and evaluation.

${ }^{a}$ Energy Policy act of 1992, Energy Policy Act of 2005, Executive Order 13423, and Energy Independence and Security Act of 2007.

${ }^{\mathrm{b}}$ http://www.military.com/base-guide/naval-air-station-whidbey-island [accessed December 15,2014]. 


\section{CONTENTS}

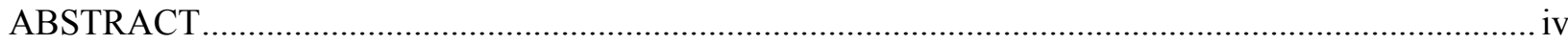

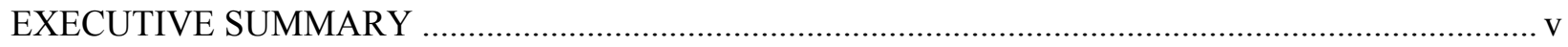

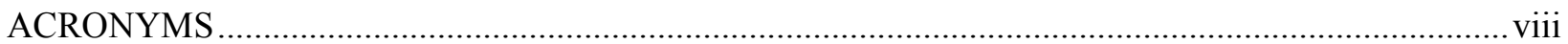

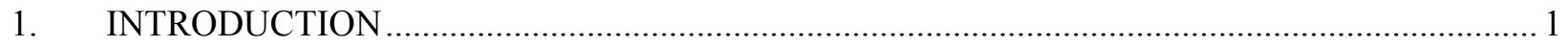

2. NAVAL AIR STATION WHIDBEY ISLAND FLEET INVENTORY SUMMARY ................... 1

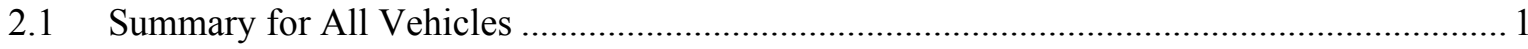

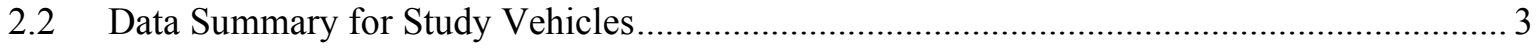

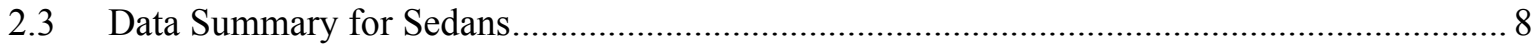

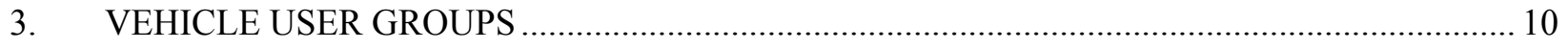

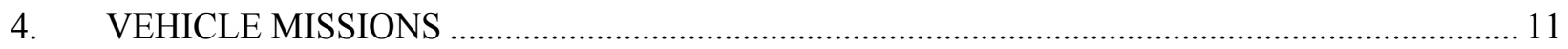

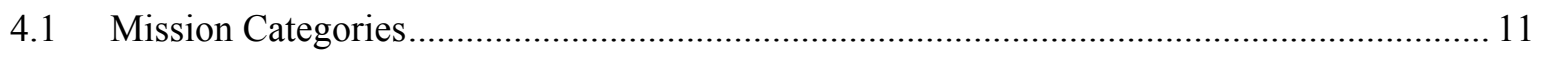

4.2 Vehicle Mission of Naval Air Station Whidbey Island Inventory …................................ 12

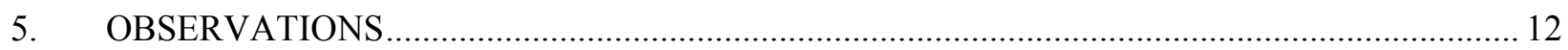

\section{FIGURES}

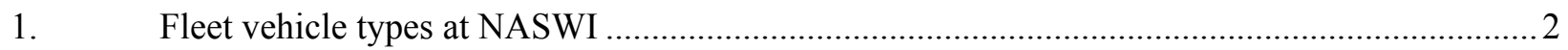

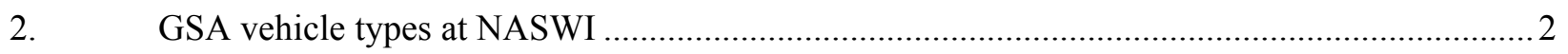

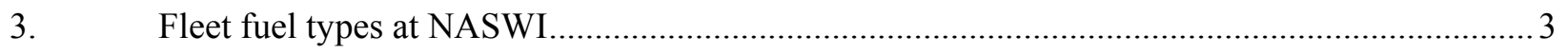

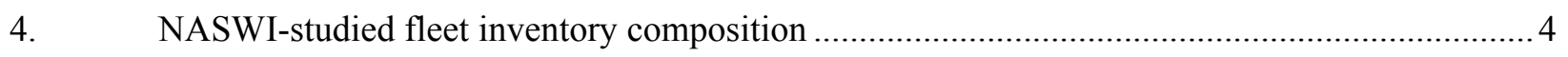

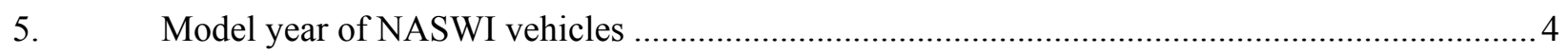

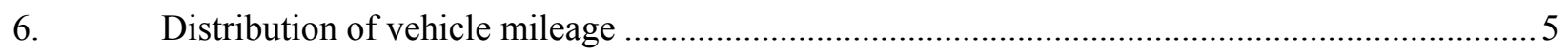

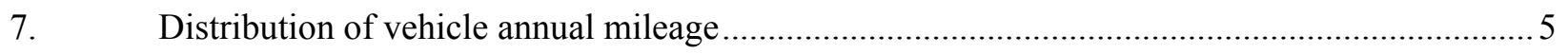

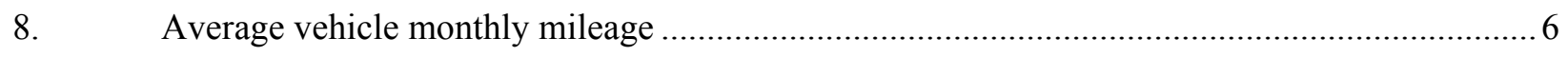

9. Projected replacement year for current fleet inventory …................................................... 6

10. Projected age and odometer reading at replacement …...................................................... 7 


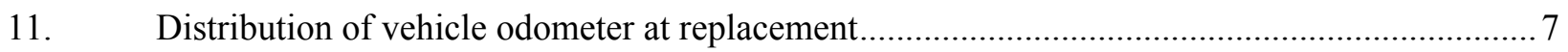

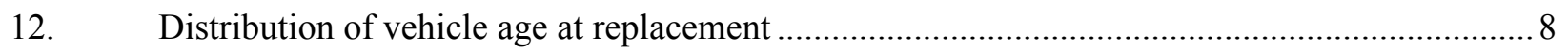

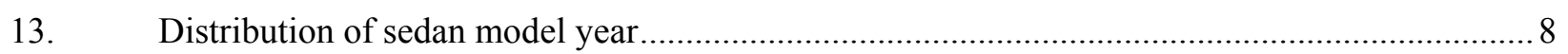

14. Monthly mileage comparison of sedans to all vehicles ........................................................ 9

15. Cumulative odometer reading distribution for sedans ......................................................... 9

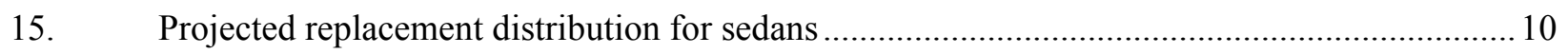

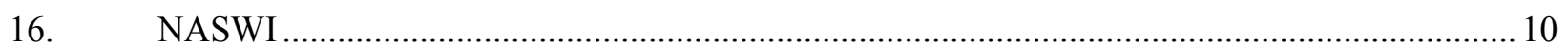

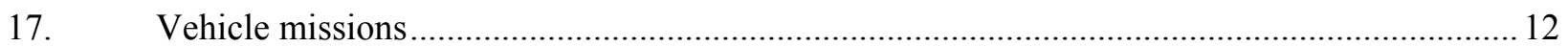

\section{TABLES}

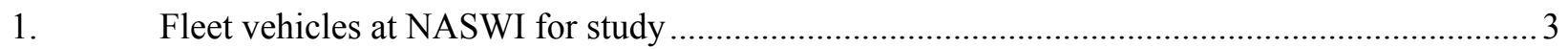

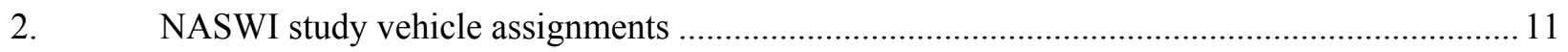

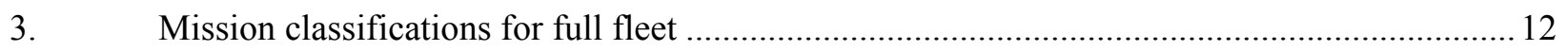

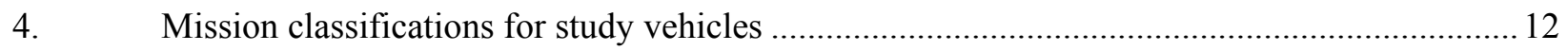




\section{ACRONYMS}

BEV battery electric vehicle

EPA U.S. Environmental Protection Agency

GSA General Services Administration

Intertek Intertek Testing Services, North America

MOU memorandum of understanding

NASWI Naval Air Station Whidbey Island

PEV plug-in electric vehicle (includes BEVs and PHEVs, but not hybrid electric vehicles)

PHEV plug-in hybrid electric vehicle

SUV sports utility vehicle 


\section{Assessment of Fleet Inventory for Naval Air Station Whidbey Island: Task 1}

\section{INTRODUCTION}

The U.S. Department of Energy and the U.S. Department of Defense signed a memorandum of understanding (MOU) on July 22, 2010, for strengthening the coordination of efforts to enhance national energy security and to demonstrate federal government leadership in transitioning the United States to a low-carbon economy. The MOU included efforts in the areas of energy efficiency, fossil fuels, alternative fuels, efficient transportation technologies and fueling infrastructure, grid security, smart grid, and energy storage.

In support of the MOU, Idaho National Laboratory, with funding provided by the U.S. Department of Energy's Vehicle Technologies Office and Federal Energy Management Program, directed Intertek Testing Services, North America (Intertek) to conduct several U.S. Department of Defense-based studies. These studies were conducted to identify potential transportation systems that are strong candidates for introduction or expansion of plug-in electric vehicles (PEVs). Intertek previously has conducted similar fleet, city, state, and countrywide studies using their EV Micro-Climate ${ }^{\circledR}$ assessment process, which consists of the following four main tasks:

- Task 1: Conduct a non-tactical vehicle fleet assessment

- Task 2: Select vehicles for mission and fleet characterizations

- Task 3: Perform a detailed assessment of the selected vehicles and charging infrastructure needs

- Task 4: Prepare adoption approach for PEVs and charging infrastructure.

The assessment of the potential for replacing Naval Air Station Whidbey Island (NASWI) fleet vehicles with PEVs starts with the characterization of fleet vehicles' missions and vehicle characteristic and was conducted through a detailed review of the fleet inventory and discussions with site personnel. This Task 1 report provides a summary and assessment of the fleet data and survey results.

PEVs generally are classified into two vehicle types: (1) battery electric vehicles (BEVs) and (2) plug-in hybrid electric vehicles (PHEVs). BEVs are vehicles where an onboard battery provides all motive power. For PHEVs, an onboard battery provides some of the motive power, but battery power is supplemented by another power source (e.g., a gasoline engine). Collectively, BEVs and PHEVs are known as PEVs.

Section 2 provides the characterization of the current fleet at NASWI. Section 2.1 presents the data summary for all fleet vehicles. Section 2.2 provides information for all sedans, light trucks, and medium trucks, which will be the detailed focus of this study. Section 2.3 further defines sedans only because they are the only vehicles currently available from the General Services Administration (GSA). Section 3 identifies the user groups for these vehicles and Section 4 provides the classification of vehicle missions and relates these missions to NASWI vehicles. Finally, Section 5 provides observations related to this current task.

\section{NAVAL AIR STATION WHIDBEY ISLAND FLEET INVENTORY SUMMARY}

\subsection{Summary for All Vehicles}

The fleet of vehicles in the inventory at NASWI consists of 324 vehicles, including non-powered trailers and material handling equipment. There currently are 20 low-speed vehicles, 66 specialty pieces of equipment (e.g., cranes, wrecker, ambulance, etc.), two buses, and 30 heavy-duty trucks (e.g., tractors, etc.) that are identified in the full fleet makeup. These categories will not be included in this study. Although PEV demonstrators of some of these vehicles exist, they are not standard PEV models or may have special charging needs for which separate analysis may be required. 
This fleet consists of 165 GSA vehicles, 153 Navy-owned vehicles, and six miscellaneous vehicles. The GSA and Navy-owned categories provide information on the vehicles; however, greater detail is provided in the U.S. Environmental Protection Agency (EPA) classifications. Using EPA definitions and general classifications, the current fleet makeup is shown in Figure 1.

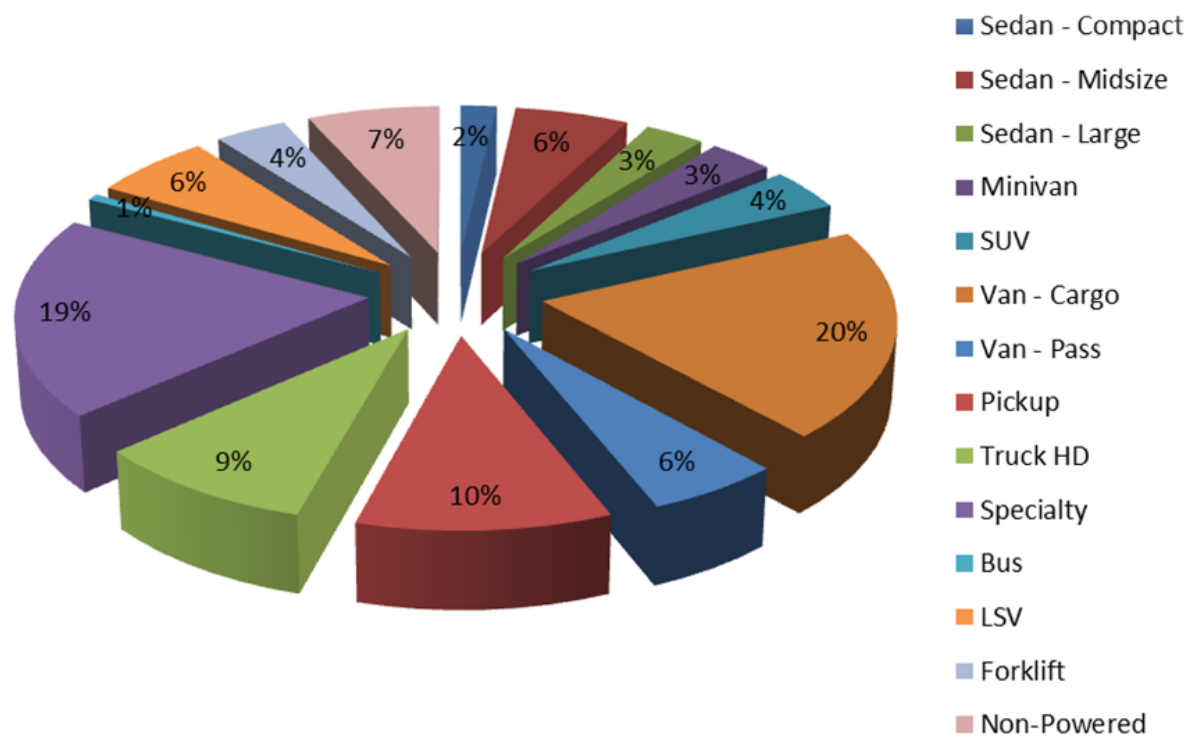

Figure 1. Fleet vehicle types at NASWI.

Figure 2 shows the classifications of the 165 GSA vehicles.
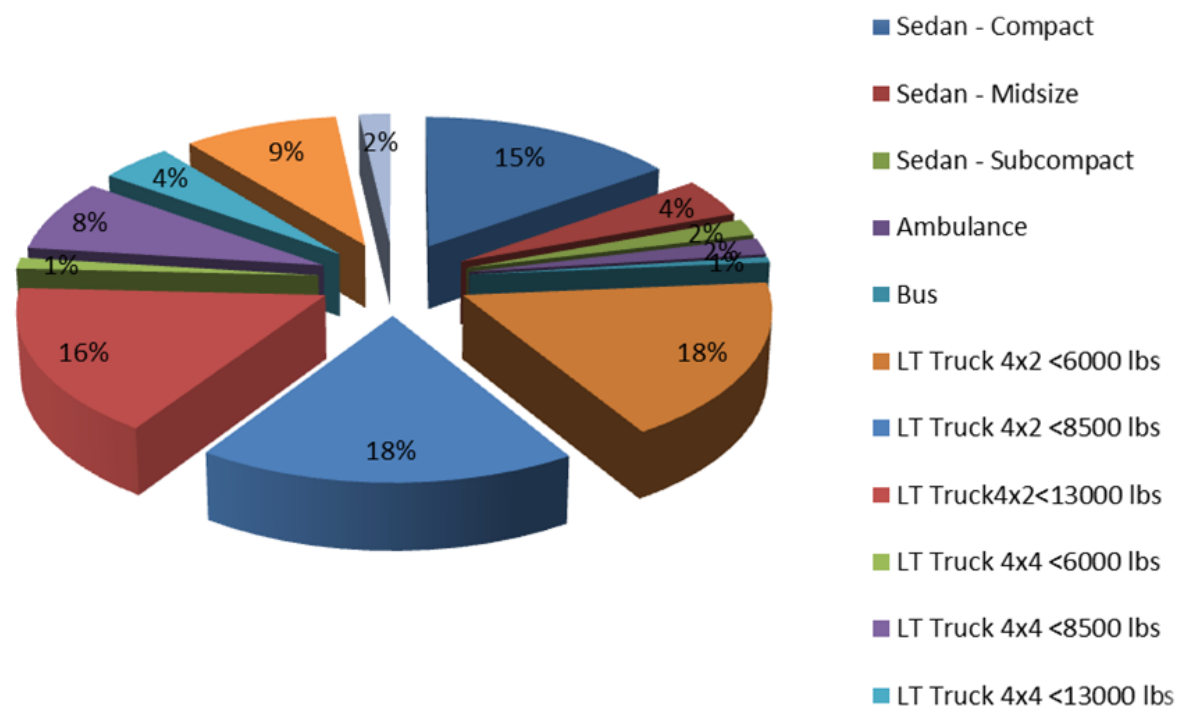

Figure 2. GSA vehicle types at NASWI.

There are some differences between the GSA list and EPA list for sedans. Specifically, GSA lists the classification G10 as compact, but the vehicles are either compact or midsize per EPA. GSA classification G11 is a midsize sedan, but all sedans at NASWI are Chevrolet Impalas that the EPA classifies as large sedans. GSA classification G12 is compact, but EPA classifies these vehicles as midsize. Finally, GSA 
classification G13 is subcompact, but EPA shows the Ford C-Max hybrid (in the NASWI inventory) as a large sedan.

The Navy-owned vehicles make up approximately one-half of the vehicles and include all low-speed vehicles, material handling equipment, a bus, the non-powered equipment, 48 specialty vehicles, 12 pickups, six cargo vans, and 38 heavy-duty trucks.

Figure 3 shows the fuel type distribution for these vehicles. As can be seen in the figure, gasoline-powered vehicles (including a significant number of ethanol/gas) comprise the majority of vehicles.

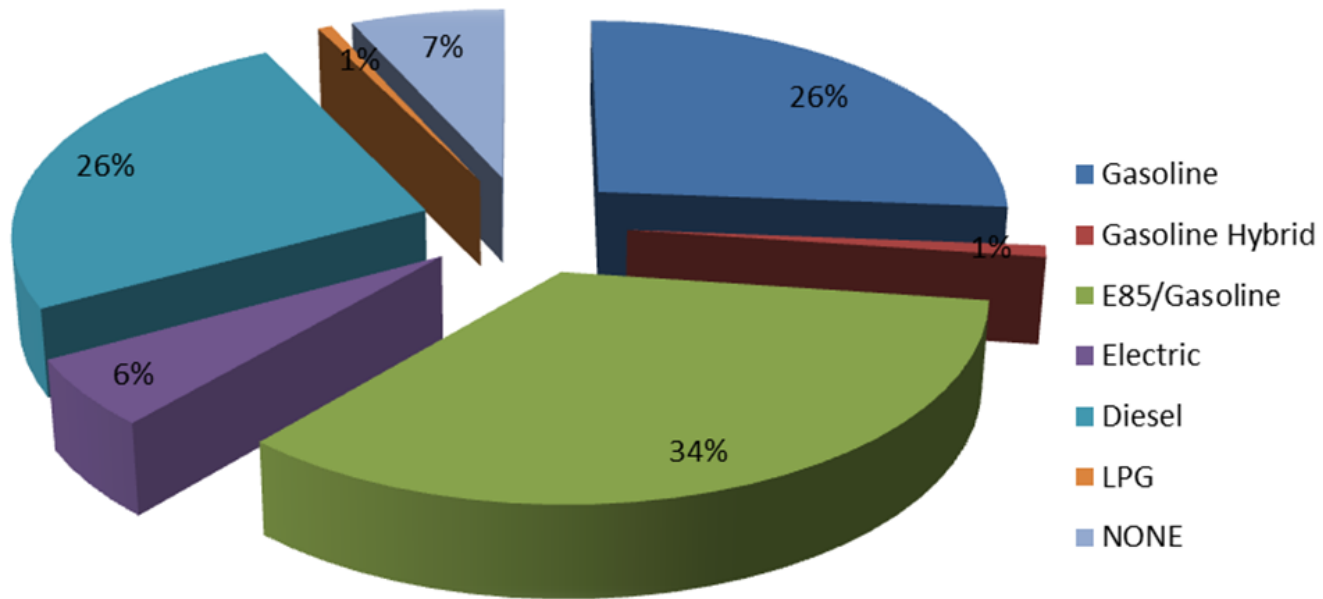

Figure 3. Fleet fuel types at NASWI.

Sedans and light trucks are powered predominantly by gasoline. These vehicle types make up the majority of the fleet and are the most likely candidates for replacement by PEVs because auto manufacturers have focused, to date, on providing PEVs of this size. The "None" fuel type is identified for the non-powered vehicles and the "Electric" fuel type are all low-speed vehicles. The two LPG-powered vehicles are forklifts.

Diesel-powered vehicles also make up a sizeable fraction of the fleet; diesel is the predominant fuel used in larger vehicles. Medium-duty trucks may be candidates for replacement by PEVs because manufacturers plan to provide more vehicles of this size in the coming years. However, certain medium-duty and all heavy-duty trucks are excluded from this analysis.

\subsection{Data Summary for Study Vehicles}

This section provides a summary for the 175 sedans, light trucks, and medium trucks (per the GSA definition) that are the focus of this study. These vehicles are most likely to have PEV models suitable for replacement in the near term. Table 1 identifies, by EPA classification, the vehicles to be studied.

Table 1. Fleet vehicles at NASWI for study.

\begin{tabular}{|c|c|c|c|c|c|c|c|c|c|}
\hline & $\begin{array}{l}\text { Sedan - } \\
\text { Compact }\end{array}$ & $\begin{array}{l}\text { Sedan - } \\
\text { Midsize }\end{array}$ & $\begin{array}{l}\text { Sedan - } \\
\text { Large }\end{array}$ & Minivan & SUV & $\begin{array}{l}\text { Van } \\
\text { Cargo }\end{array}$ & Van Pass & Pickup & Total \\
\hline Qty & 6 & 19 & 10 & 11 & 13 & 55 & 19 & 42 & 175 \\
\hline Percent & $3 \%$ & $11 \%$ & $6 \%$ & $6 \%$ & $7 \%$ & $31 \%$ & $11 \%$ & $24 \%$ & $100 \%$ \\
\hline
\end{tabular}

Figure 4 shows the composition of the fleet vehicles that are the focus of this study. Fully $20 \%$ of the vehicles are sedans, $13 \%$ are minivans or sports utility vehicles (SUVs), $24 \%$ are pickups, and $42 \%$ are vans. 


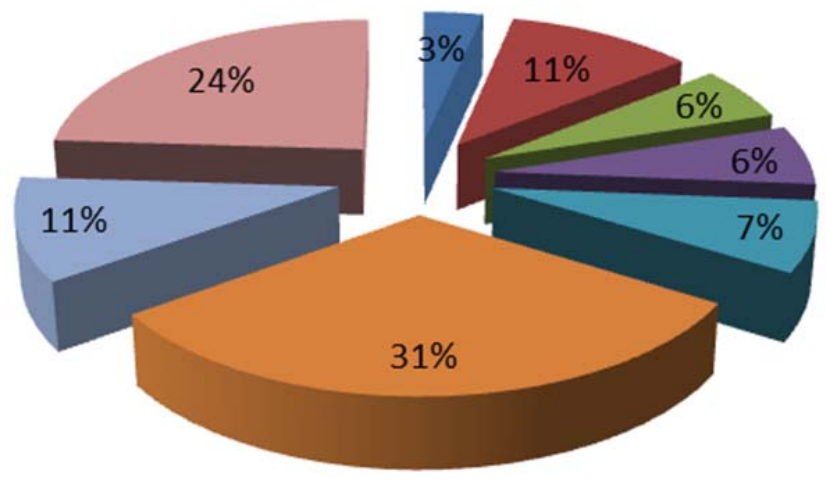

- Sedan - Compact

- Sedan - Midsize

- Sedan - Large

घ Minivan

a SUV

van - Cargo

- Van - Pass

Pickup

Figure 4. NASWI-studied fleet inventory composition.

The model years of the vehicles under study are shown in Figure 5. The age of the current fleet is rather young, with $65 \%$ of the vehicles having a model year 2010 or newer. Nevertheless, $9 \%$ are more than 10 years old, with the oldest vehicles in operation being a Chevrolet pickup of model year 1976 with last odometer reading over 78,000 miles.

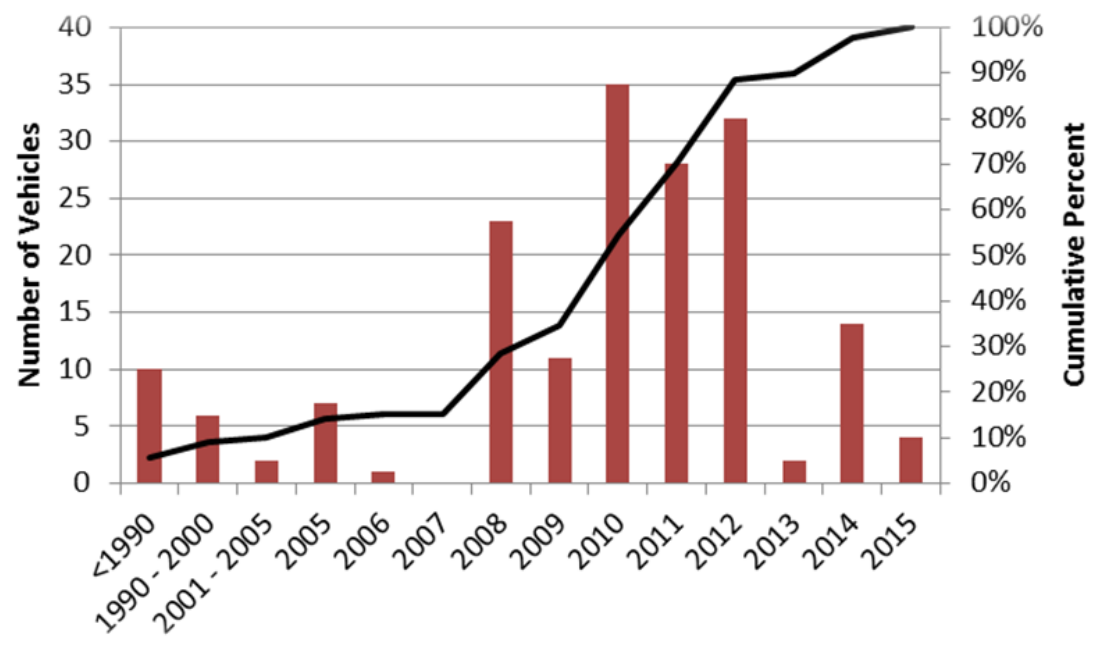

Figure 5. Model year of NASWI vehicles.

The distribution of the most recent odometer readings of the 175 vehicles is shown in Figure 6 . The odometer readings of 100 vehicles (57\%) show less than 20,000 miles. On the other hand, six vehicles have recent odometer readings exceeding 100,000 miles, with the highest at 138,260 miles. Five of these six are enforcement vehicles. See Section 3 for further discussion of vehicle mission related to enforcement activities.

The annual mileage of the vehicles was calculated using the latest odometer reading and dividing by the age of the vehicle. Figure 7 shows the cumulative distribution of the vehicles' annual mileage. Some $68 \%$ of the vehicles are driven less than 5,000 miles each year, which is an average of less than 100 miles per week. The eight vehicles with the heaviest usage are used in enforcement activities and exceed 20,000 miles per year. 


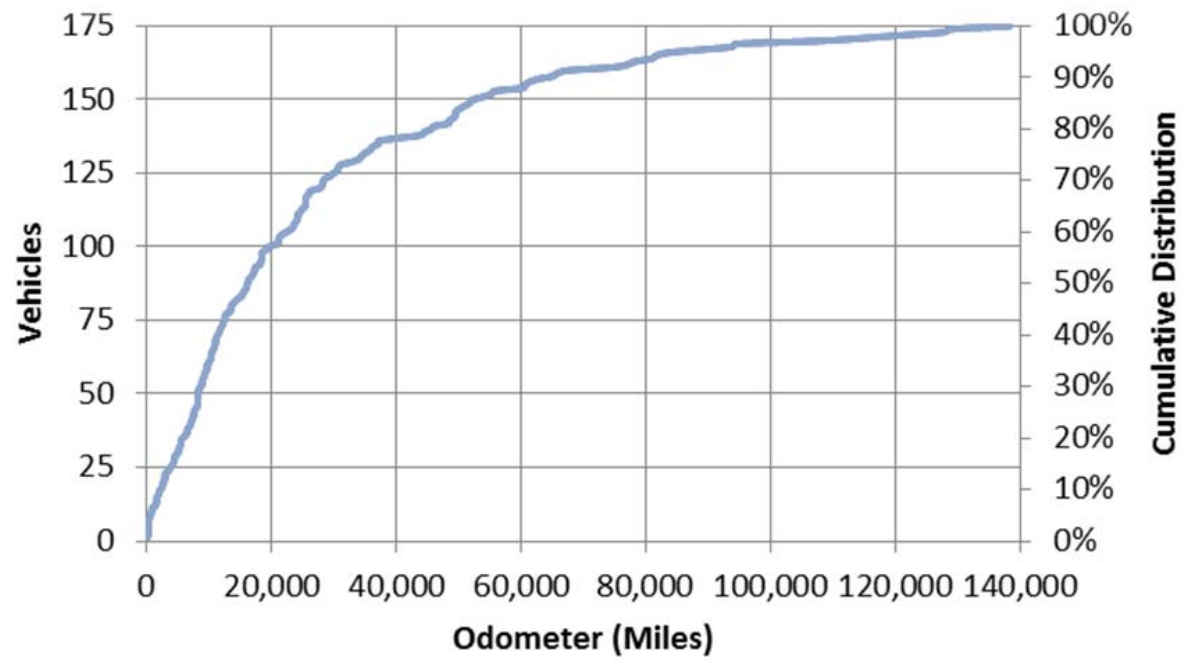

Figure 6. Distribution of vehicle mileage.

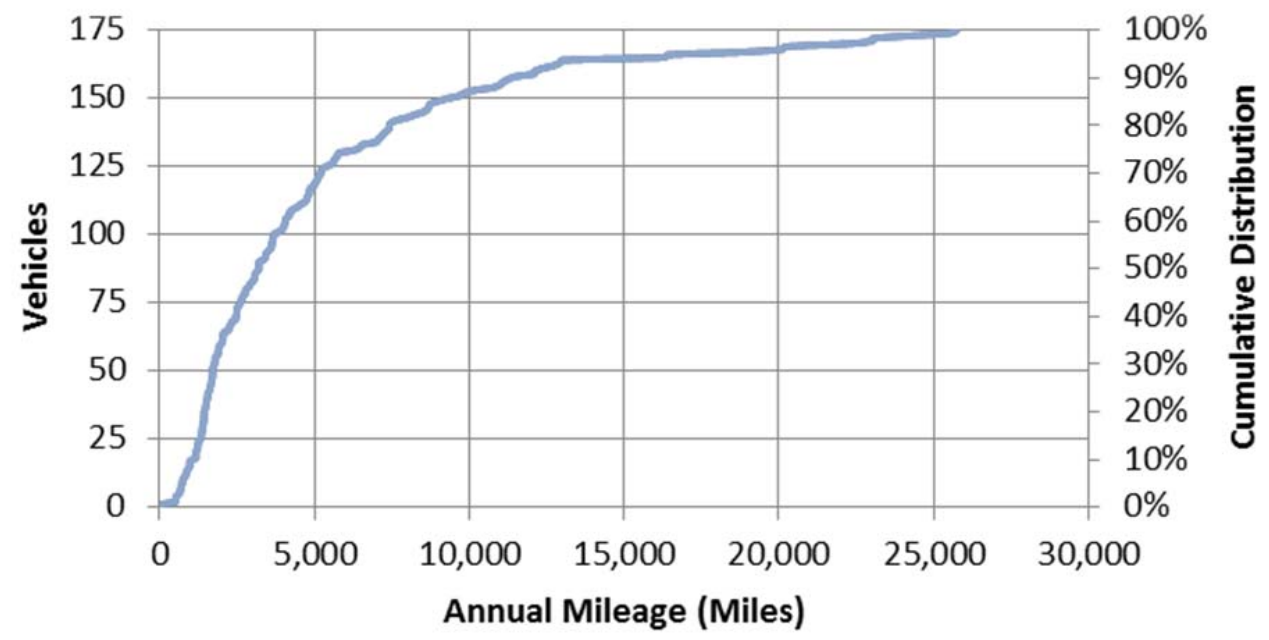

Figure 7. Distribution of vehicle annual mileage.

Of particular interest is the monthly mileage of the studied fleet (Figure 8). If one assumes a battery range of 70 miles for a BEV and 21 working days per month, then a vehicle that consistently travels the same distance each day would have to travel greater than approximately 1,500 miles per month to exceed the batter capacity. As shown in Figure 8, approximately 95\% of NASWI cars, light trucks, and medium trucks have average travel that is less than 1,500 miles per month. Therefore, barring charging constraints associated with the timing of daily mission activities, payload requirements, and range issues associated with off-base trips, a significant number of vehicles should be eligible for replacement by BEVs.

GSA publishes minimum requirements for vehicle replacement. NASWI typically has exceeded these requirements prior to replacing vehicles. Extrapolating the annual miles from recent odometer readings, with GSA requirements as a minimum, the replacement year of these fleet vehicles was projected. Note that an upper limit of 2030 ( 15 years away) was arbitrarily used as the replacement of any remaining existing vehicles. Figure 9 shows the projected number of vehicles to be replaced each year. This information will be used in Task 4 to present a replacement approach. 


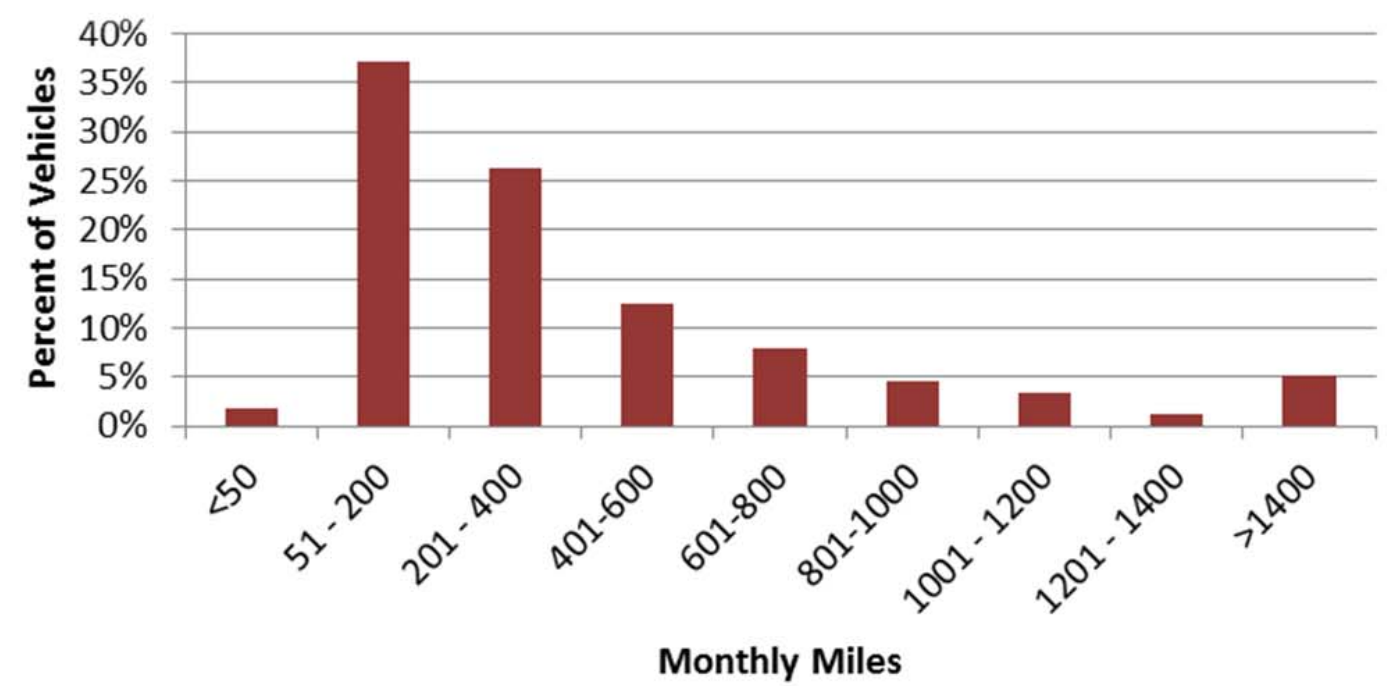

Figure 8. Average vehicle monthly mileage.

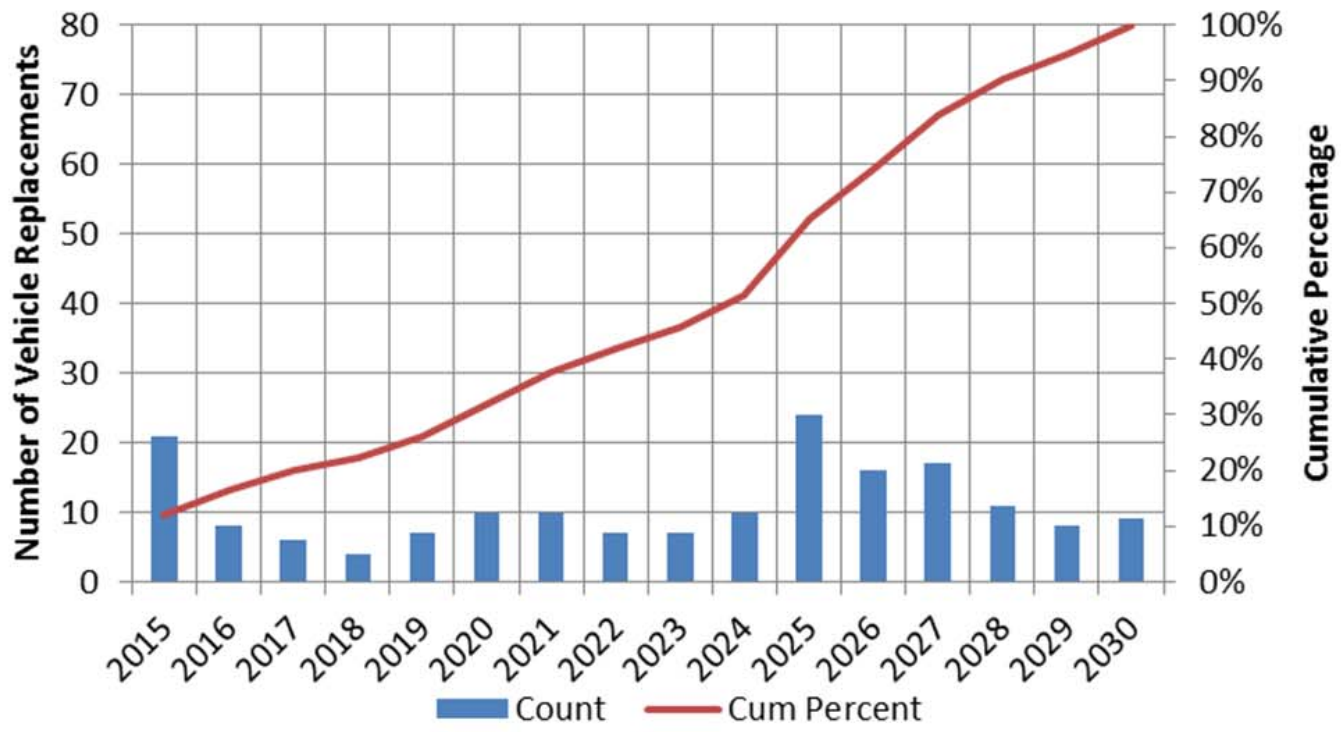

Figure 9. Projected replacement year for current fleet inventory.

It has been noted that a significant number of vehicles of newer model years creates the peak seen in 2025 and the older model years of a significant number of vehicles sets the peak for 2015. The projected age and odometer reading of the vehicles at replacement are shown in Figure 10. For example, Vehicle \#151 (G10-3590P - Chevrolet Malibu) is projected to be replaced at age six, with an odometer reading of 78,473 miles. The minimum GSA requirements for this vehicle include 3 years and 36,000 miles, 5 years and any mileage, or any age and 75,000 miles. The projected replacement exceeds all three GSA requirements. 


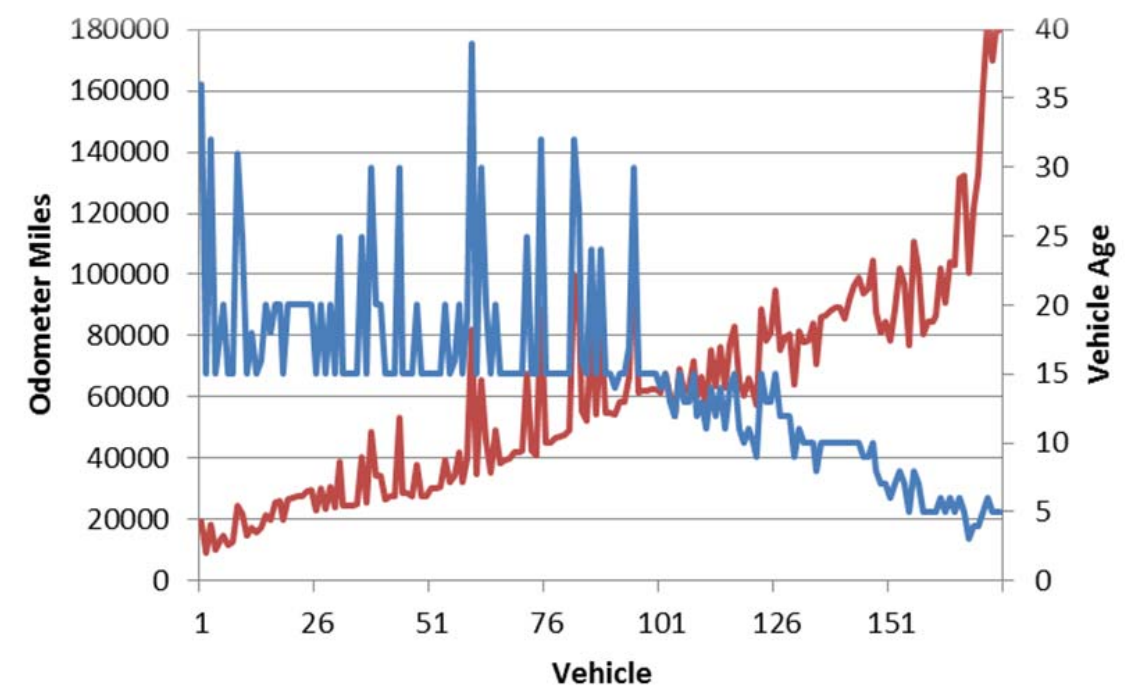

Odometer at Replacement _ Age at Replacement

Figure 10. Projected age and odometer reading at replacement.

For the most part and as would be expected, the age of the vehicle at replacement varies inversely with the odometer reading. As shown in Figure 5, many current vehicles have a significant age (Figure 10). Vehicles that have high usage are likely to be replaced at a younger age than vehicles with low usage.

Figure 11 shows the cumulative distribution of vehicle odometer readings at replacement. The mean and median projected odometer readings of the replaced vehicles are 58,384 and 60,914 miles, respectively.

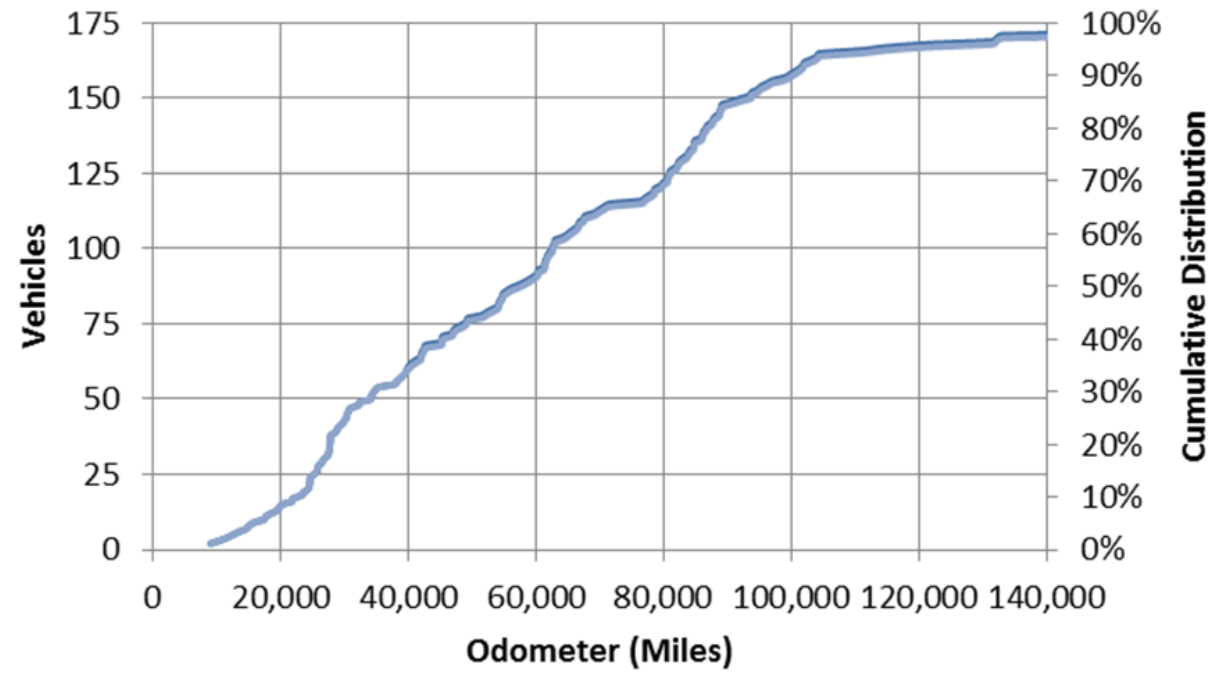

Figure 11. Distribution of vehicle odometer at replacement.

Figure 12 shows the cumulative distribution of vehicle age at replacement. The mean and median ages of the replaced vehicle are 15 years old. The age of the vehicle at replacement almost always exceeds the GSA minimum requirements of 3 to 10 years (depending on vehicle type). The odometer reading at replacement exceeds the minimum for sedans $(36,000)$ and is near the minimum for light trucks $(65,000)$. This again reflects the relatively low annual travel usage of the vehicles. 


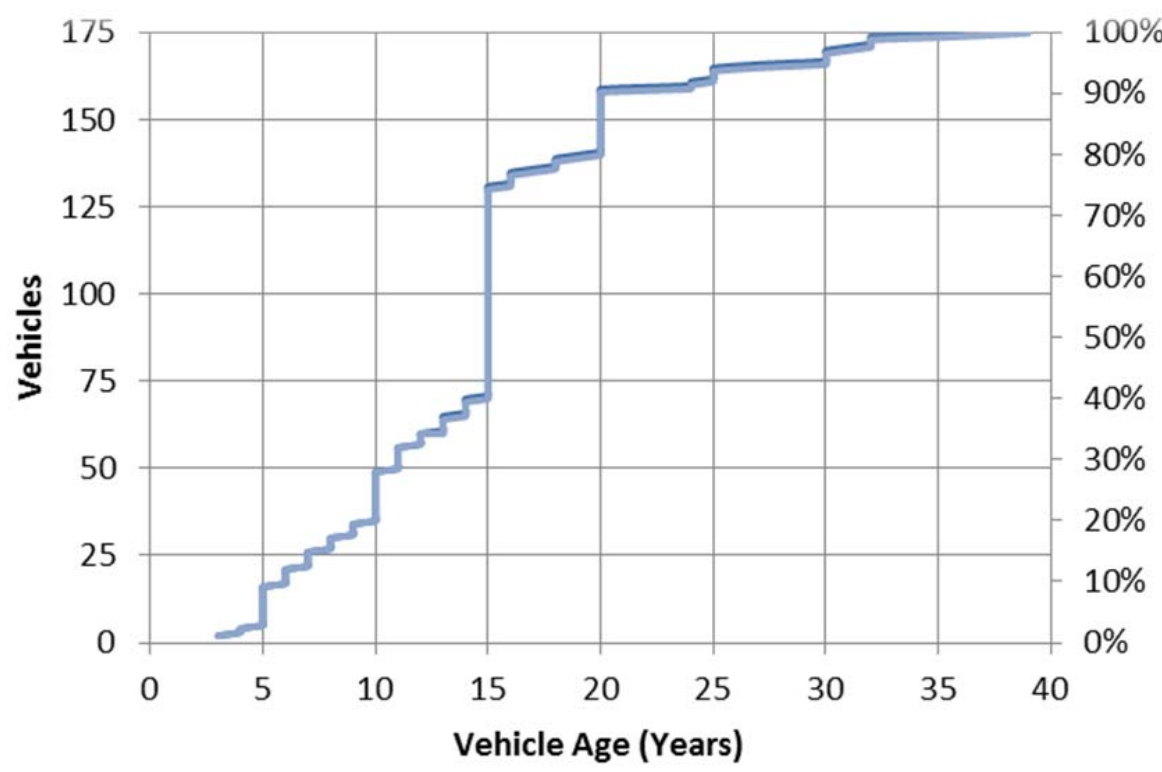

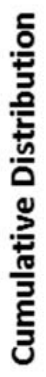

Figure 12. Distribution of vehicle age at replacement.

\subsection{Data Summary for Sedans}

This section provides a summary of the data for sedans. Sedans are reviewed separately because, at this writing, only sedan-type vehicles populate the GSA list for PEVs.

Thirty-five sedans are in the fleet of vehicles. Figure 13 shows the distribution of sedan model years. Fully $57 \%$ are model year 2012 or newer.

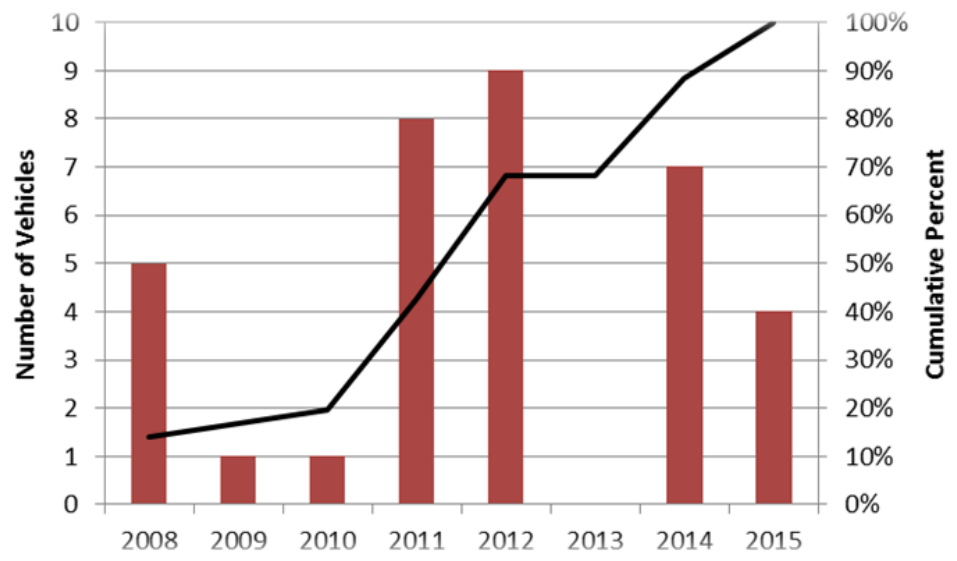

Figure 13. Distribution of sedan model year.

Similar to Section 2.2, sedans also have a monthly mileage distribution that indicates that the range generally should not be a concern. Figure 14 shows that the sedans generally have higher monthly usage than the average of all the vehicles studied. 


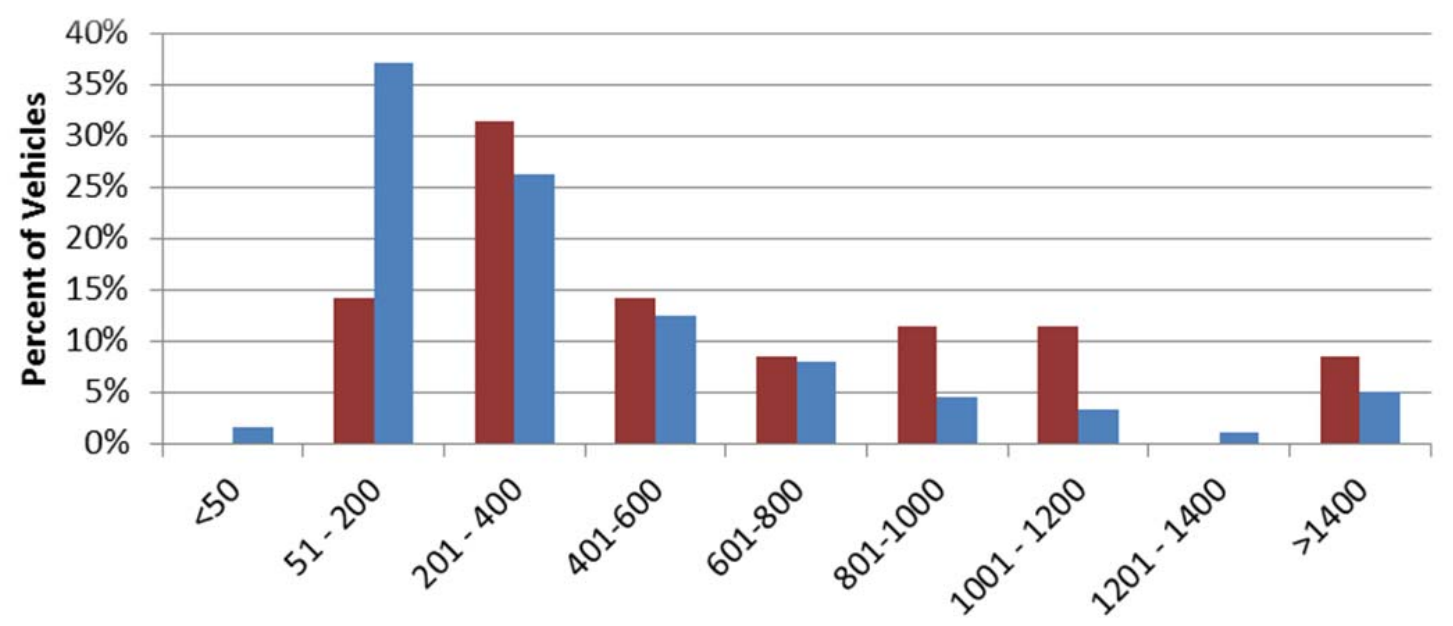

Monthly Miles

Sedans all Vehicles

Figure 14. Monthly mileage comparison of sedans to all vehicles.

Figure 15 shows the projected year of replacement for the sedans. The peaks in the next few years are due to the age of many of the vehicles, coupled with several vehicles having high mileage.

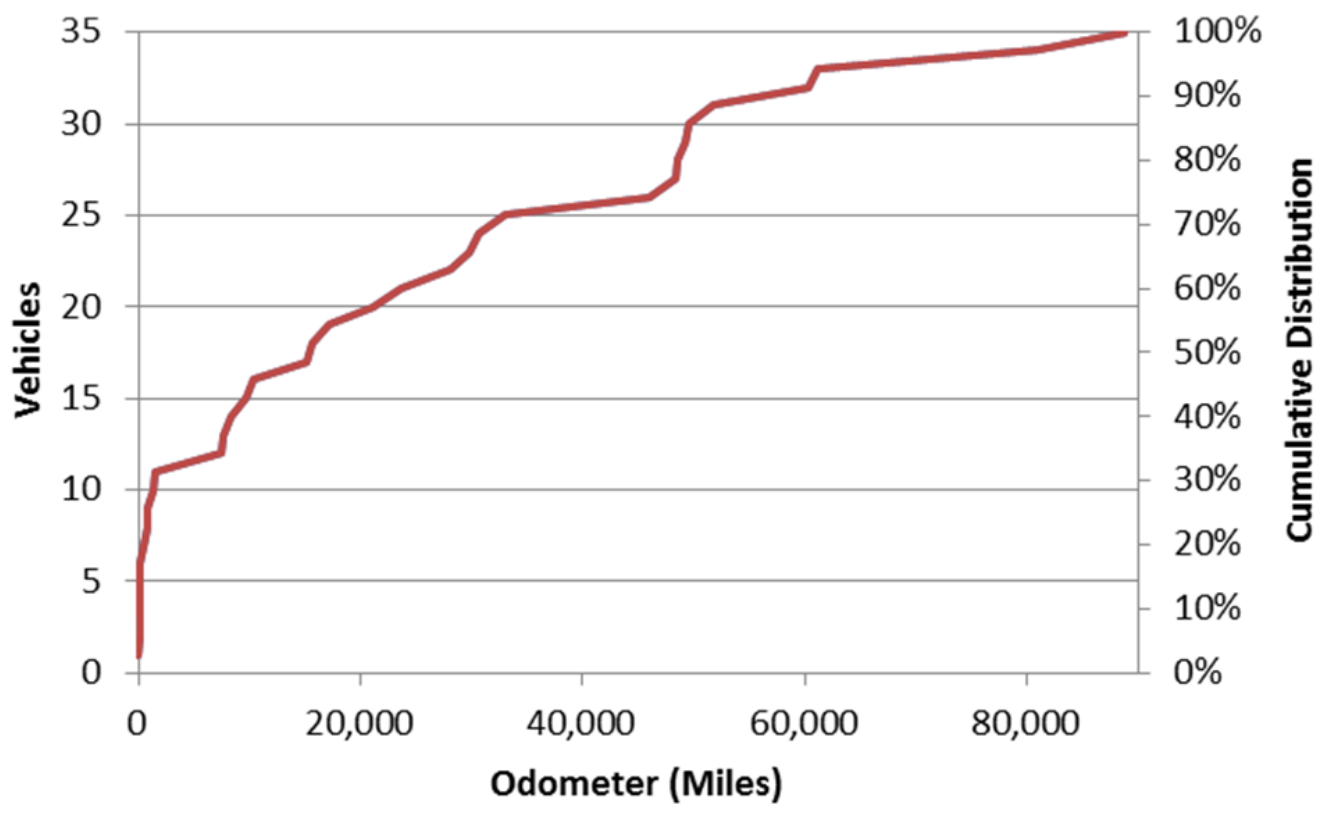

Figure 15. Cumulative odometer reading distribution for sedans.

Figure 16 shows the projected distribution of replacements for the fleet of sedans. As before, the projected age of replacement will be used in future reports to provide a replacement approach for incorporating PEVS. 


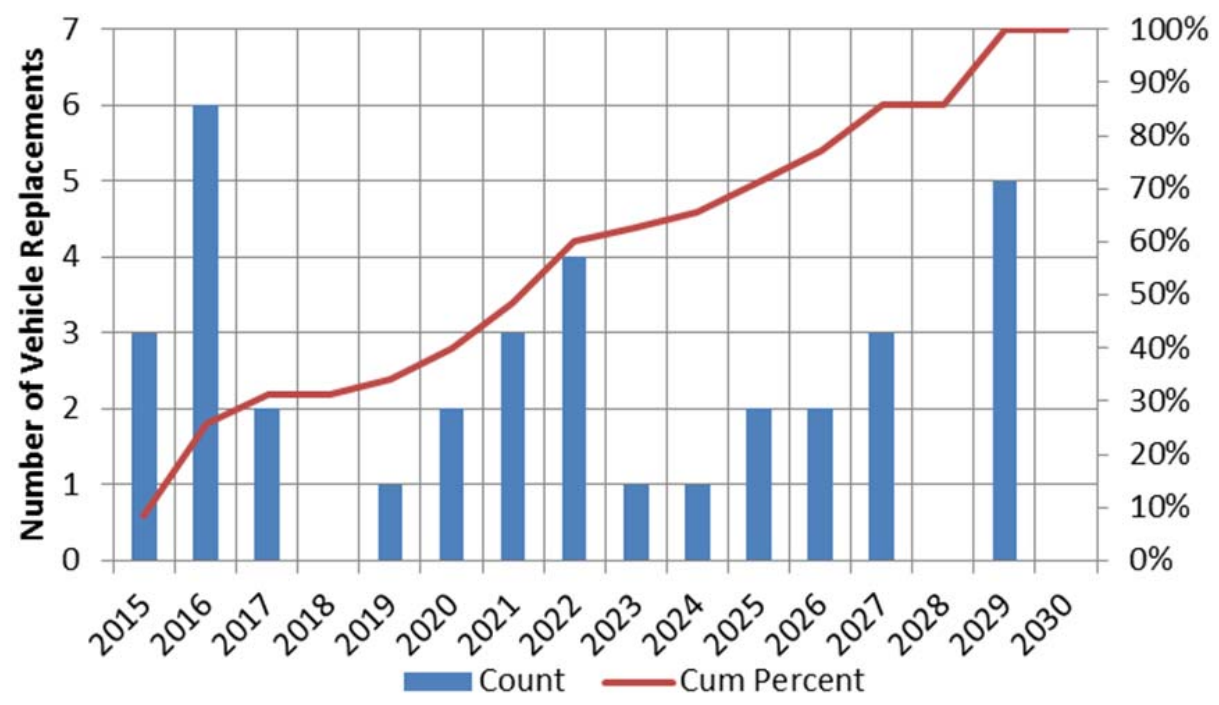

䓌

Figure 15. Projected replacement distribution for sedans.

\section{VEHICLE USER GROUPS}

NASWI is located on Whidbey Island on the Puget Sound in Washington State. It is the premier naval aviation installation in the Pacific Northwest and home of all Navy tactical electronic attack squadrons flying the EA-6B Prowler and EA-18G Growler. In addition, there are four P-3 Orion Maritime Patrol squadrons and two Fleet Reconnaissance squadrons flying the EP-3E Aries. ${ }^{3}$

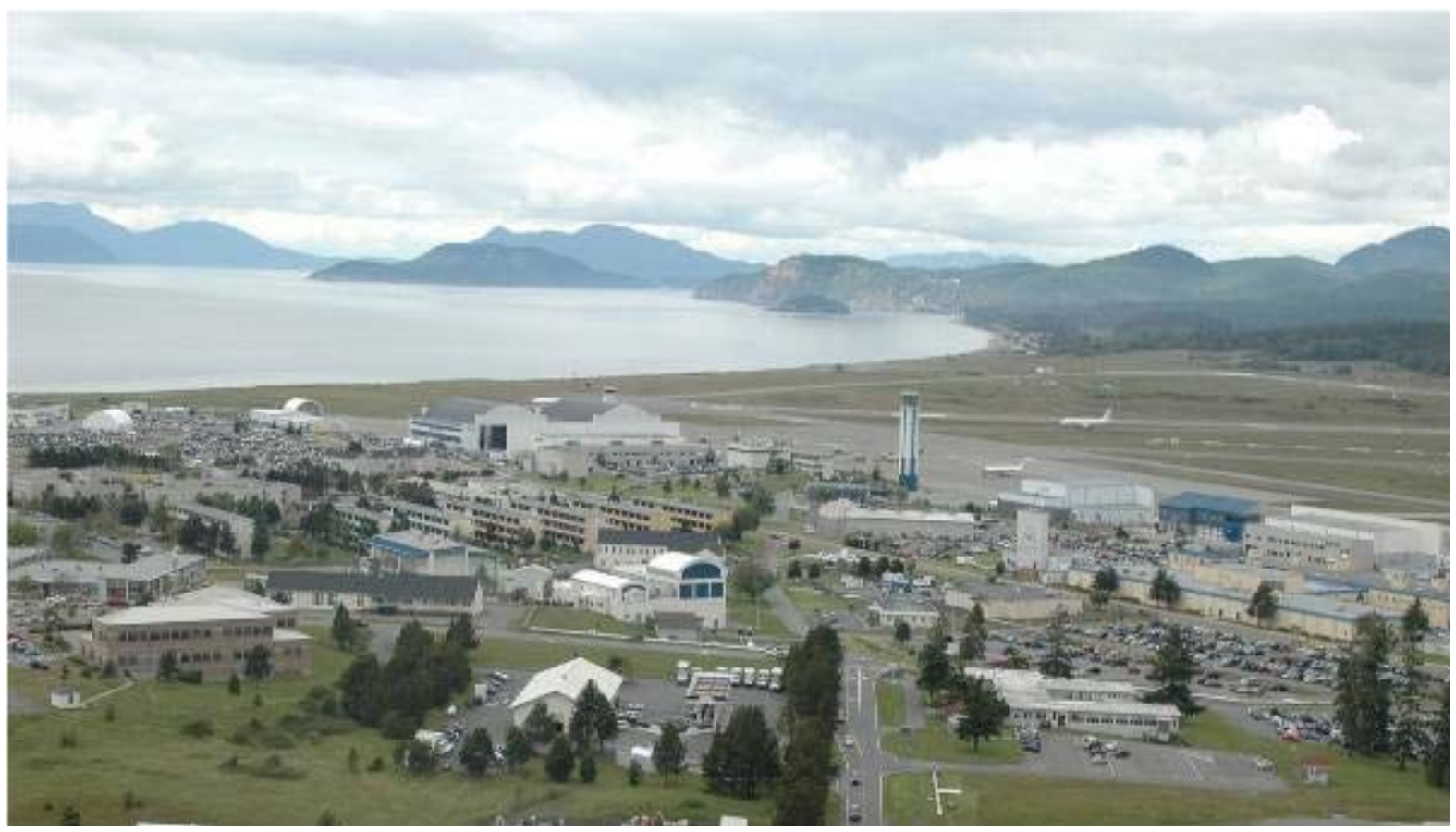

Figure 16. NASWI.

The 25 tenant commands (commands) include the Electronic Attack Wing, the Patrol and Reconnaissance Wing, Fleet Readiness Center, Navy Munitions Command, Navy Operational Support

\footnotetext{
${ }^{3}$ http://www.military.com/base-guide/naval-air-station-whidbey-island [accessed December 26, 2014]
} 
Center, Naval Criminal Investigative Service, Navy Region Northwest Fire and Emergency Services, Naval Hospital Oak Harbor, and others.

The Naval Air Station departments and divisions (departments) support the operations of tenant command activities and transient aircraft. These include providing air traffic control, range scheduling, ground electronics and communications maintenance, air cargo and passenger service, arresting gear maintenance, search and rescue operations, and other functions.

The non-tactical fleet is managed by the Transportation group of Naval Facilities Engineering Command Northwest. The commands operate 110 vehicles and the departments operate the remaining 214 vehicles, which includes all pool vehicles. Of the vehicles in the study group, the commands operate 69 vehicles and the departments operate 106 vehicles. Table 2 shows the assignments of the vehicles in this study.

Table 2. NASWI study vehicle assignments.

\begin{tabular}{|l|c|c|c|c|c|c|c|c|c|}
\hline & $\begin{array}{c}\text { Sedan - } \\
\text { Compact }\end{array}$ & $\begin{array}{c}\text { Sedan - } \\
\text { Midsize }\end{array}$ & $\begin{array}{c}\text { Sedan - } \\
\text { Large }\end{array}$ & Minivan & SUV & $\begin{array}{c}\text { Van } \\
\text { Cargo }\end{array}$ & $\begin{array}{c}\text { Van } \\
\text { Pass }\end{array}$ & Pickup & Total \\
\hline Commands & 2 & 4 & 1 & 7 & 2 & 31 & 5 & 17 & 69 \\
\hline Departments & 4 & 15 & 9 & 4 & 11 & 24 & 14 & 25 & 106 \\
\hline Total & 6 & 19 & 10 & 11 & 13 & 55 & 19 & 42 & 175 \\
\hline
\end{tabular}

\section{VEHICLE MISSIONS}

\subsection{Mission Categories}

The vehicle mission is an important characteristic in the fleet study. Information used to define the vehicle mission includes the vehicle's configuration, vehicle use, classification per 40 CFR Part 600.31582 and EPA, the participating agency use, and general vehicle use. Based on fleet information gathered, Intertek has established the following seven mission/vehicle categories for analysis (examples are depicted in Figure 16):

1. Pool vehicles: A pool vehicle is any automobile (other than the low-speed vehicles identified below) manufactured primarily for use in passenger transportation, with not more than 10 passengers.

2. Enforcement vehicles: Vehicles specifically approved in an agency's appropriation act for use in apprehension, surveillance, police, or other law enforcement work. This category also includes site security vehicles, parking enforcement, and general use, but the vehicles are capable of requirements to support enforcement activities.

3. Support vehicles: Vehicles assigned to a specific work function or group to support the mission of that group. Vehicles are generally passenger vehicles or light-duty pickup trucks and may contain after-market modifications to support the mission.

2. Transport vehicles: Light, medium, or heavy-duty trucks used to transport an operator and tools or equipment of a non-specific design or nature. The vehicle's uses include repair, maintenance, or delivery.

3. Specialty vehicles: Vehicles designed to accommodate a specific purpose or mission (such as ambulances, mobile cranes, and handicap controls).

4. Shuttles/buses: Vehicles designed to carry more than 12 passengers and further outlined in 49 CFR 532.2.

5. Low-speed vehicles: Vehicles that are legally limited to roads with posted speed limits up to $45 \mathrm{mph}$ and that have a limited load-carrying capability. 


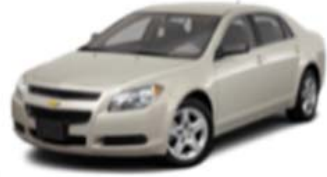

Pool Vehicle

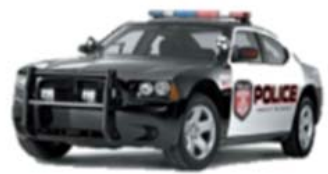

Enforcement Vehicle

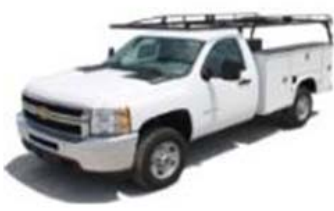

Support Vehicle

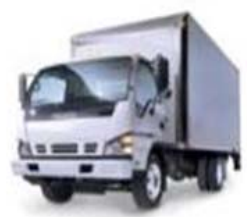

Transport Vehicle

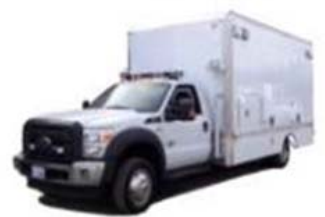

Specialty Vehicle

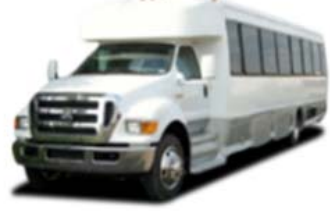

Shuttle / Bus

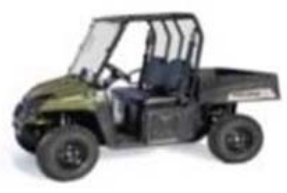

Low Speed

Vehicles

Figure 17. Vehicle missions.

\subsection{Vehicle Mission of Naval Air Station Whidbey Island Inventory}

The mission classifications for the full inventory of vehicles (less non-powered and forklift) is shown in Table 3. This is not exact because some heavy-duty trucks may be in either the transport or the specialty categories. However, the approximate mission can be of value in determining desirability of PEV replacements.

Table 3. Mission classifications for full fleet.

\begin{tabular}{ccccccccc}
\hline & Pool & Support & Enforcement & Transport & Specialty & Bus & Low-Speed Vehicle & Total \\
\hline Total & 21 & 138 & 25 & 22 & 66 & 2 & 20 & 294 \\
\hline
\end{tabular}

For the vehicles in the study, the mission classifications are shown in Table 4.

Table 4. Mission classifications for study vehicles.

\begin{tabular}{lccccc}
\hline & Pool & Support & Enforcement & Transport & Total \\
\hline Commands & & 56 & & 13 & 69 \\
Departments & 20 & 60 & 25 & 1 & 106 \\
Total & 20 & 116 & 25 & 14 & 175 \\
\hline
\end{tabular}

\section{OBSERVATIONS}

The NASWI non-tactical fleet contains 175 vehicles for which PEV types are currently available or expected to be available in the next few years. A 60-group subset of this fleet will be selected for further study for determination of mission and usage characteristics as the focus of Task 2. 